\title{
En la variedad está el gusto. El feminismo, entre la pluralidad y la reafirmación de los compromisos comunes*
}

\author{
Variety is the spice. Feminism, between plurality \\ and the reaffirmation of common compromises
}

Na variedade está o prazer. O feminismo, entre a pluralidade e a reafirmação dos compromissos comuns

\footnotetext{
* Trabajadora social de la Universidad del Valle, Magister en Poder y Sociedad desde la Problemática del Género en la Universidad Nacional de Rosario (Argentina). Con intereses investigativos en Sexualidades y géneros y Feminismos en América Latina. Correo electrónico: akaneo11@gmail.com

${ }^{* *}$ Este artículo es producto de la investigación Los movimientos socio-sexuales y las agendas de inclusión social en Latinoamérica: los casos colombiano y argentino, realizada entre el 2012 y el 2014 como parte de la investigación para optar por el título de tesis de maestría en la Universidad Nacional de Rosario (Argentina) en el 2014. Artículo de investigación recibido el 02/02/2015 y aceptado el 15/07/2015.
} 


\section{Cómo citar}

GranAdos BARCO, A. (2016). En la variedad está el gusto. El feminismo, entre la pluralidad y la reafirmación de los compromisos comunes. Revista CS, no. 18, pp. 85-106.

Cali, Colombia: Facultad de Derecho y Ciencias Sociales, Universidad Icesi. 


\section{Resumen}

Abstract

Resumo

El siguiente artículo se aproxima a los caminos recorridos por las políticas feministas en distintos momentos históricos; con la intención, por un lado, de generar posicionamientos en relación a la actualidad de un movimiento feminista plural que ha provocado críticas y autocríticas; por otro lado, de reexaminar conceptos claves de múltiples modelos de lucha contra la desigualdad y de la configuración de un sujeto del feminismo para nada homogéneo. En este sentido, se proponen reflexiones dirigidas a resaltar aquellos núcleos comunes que han sido y siguen siendo continuidades en un ambiente de rupturas, reconociendo la validez política que conservan hoy como compromisos compartidos y la pertinencia que tienen en las realidades latinoamericanas.

\section{PALABRAS CLAVE:}

Feminismo de la multiplicidad de las diferencias | género | sexo | poder | política y heterosexualidad obligatoria

The following article approaches the paths traveled by the feminist policies through different historical times; with the intention, on one side, to create statements related to the present of a plural feminist movement that has caused criticism and self-criticism; on the other hand, to re-evaluate key concepts from multiples fight models against inequality and from the composition of a non-homogeneous feminism subject. In this sense, reflections aimed to highlight those common nuclei that have been and remain being continuities on a broken environment, recognizing the political validity that preserves nowadays such as shared commitments and the relevance they have in Latin American realities

\section{KEYWORDS:}

Feminism of the differences' multiplicity | gender | sex | power | politics and mandatory heterosexuality

O seguinte artigo se aproxima aos caminhos percorridos pelas políticas feministas em diferentes momentos históricos; com a intenção, por um lado, de gerar posicionamentos relacionados à atualidade de um movimento feminista plural que tem provocado críticas e 
autocríticas; por outro lado, de reexaminar conceitos chaves de múltiplos modelos de luta contra a desigualdade e da configuração de um sujeito do feminismo para nada homogêneo. Neste sentido, propõem-se reflexões orientadas a destacar aqueles núcleos comuns que foram e continuam sendo continuidades em um ambiente de rupturas, reconhecendo a validade política que conservam hoje como compromissos compartilhados e a pertinência que têm nas realidades latino-americanas.

\section{PALAVRAS CHAVES:}

Feminismo da multiplicidade das diferenças | gênero | sexo | poder | política e heterossexualidade obrigatória 


\section{Introducción}

El conjunto de rupturas y discontinuidades vividas por los feminismos en diferentes momentos históricos y sociales ha sido desencadenado no sólo por elementos contextuales ajustados a órdenes políticos, económicos y socioculturales, sino por revisiones internas y autocríticas que develan un movimiento cercado por una diversidad de paradojas. Tales confrontaciones han conducido al entendimiento del carácter institucional de diversos sistemas de opresión como el heterosexismo, el racismo, el capitalismo, el colonialismo y las diferentes complicidades respecto al feminismo hegemónico, propio de las visiones occidentales.

Sin la intención de quebrantar el movimiento feminista, sino la de examinarlo desde una autocrítica, Butler considera que estas iniciativas "prometen una vida más democrática e integradora para el movimiento" (Butler, 2007: 7). Aun así, los debates actuales se preocupan por el florecimiento de pluralidad de apuestas en nombre del feminismo, que generan una sensación de dispersión, de pérdida o abandono de aquellas líneas más identificables y mencionables en el movimiento: las de la igualdad o de la diferencia. En la actualidad no existe un modelo único de lucha contra la desigualdad, ni un sujeto del feminismo definido de manera uniforme; más bien coexisten múltiples luchas, diferentes entre sí, como son diferentes las mujeres según su condición de clase, etaria, cultural, étnica, y su opción sexual.

En el intento de desmitificar la variedad de feminismos como una realidad contraproducente, desradicalizante o cada vez más moderada y light, nos proponemos en las siguientes reflexiones resaltar aquellos núcleos comunes o puntos neurálgicos que han sido y continúan vigentes en un ambiente de rupturas y divisiones. El reconocimiento de la validez política que conservan hoy los elementos compartidos, destacando su pertinencia en el contexto latinoamericano.

Para este propósito haremos un recorrido por las políticas feministas de distintos momentos históricos, con la intención de destacarlas como antecedentes de la discusión. También puntualizaremos en las re-conceptualizaciones derivadas del feminismo crítico desarrollado desde la década de los ochenta, con tal de acercarnos a un panorama feminista diverso, crítico, auto-crítico y con implicaciones en las realidades latinoamericanas. Por último, intentaremos retomar aquellos elementos comunes o compartidos en los caminos recorridos y que bajo nuestra consideración vale la pena destacar por su potencial político y por su pertinencia en las realidades regionales actuales. Sostendremos entonces que el marco actual del feminismo es sumamente diverso, dadas las múltiples apuestas lanzadas en su nombre, y que siguen siendo compromisos comunes: poner fin al patriarcado, bien sea considerado como sistema de dominación originario o como estructura de poder intersectada a otras dominaciones; romper con la adscripción sociocultural del sexo, el género y las identidades a las esferas íntimas 
y naturales; comprender el género como uno de tantos modos a través del cual opera el poder y discutir a profundidad el carácter institucional y obligatorio de la heterosexualidad en distintos escenarios sociales.

\section{Antecedentes}

Sin el ánimo de aleccionar sobre la historia del feminismo o de plantear una secuencia de etapas cada una más evolucionada que la anterior, nos proponemos simplemente echar mano de algunos referentes de las trayectorias de un feminismo que ha sido y sigue siendo heterogéneo. Sus luchas y planteamientos teóricos y políticos, reexaminados desde cuatro grandes corrientes occidentales (el feminismo de la igualdad, el reflujo de las luchas feministas, el feminismo de la segunda ola y el feminismo de la multiplicidad de diferencias) que sistematizan Bellucci y Rapisardi (2001) en Alrededor de la identidad, las luchas políticas del presente; complementadas desde la historia de las mujeres y la epistemología feminista.

A finales del siglo XIX y principios del XX, el feminismo de la igualdad es la corriente inicial de la propuesta de equiparar ambos sexos en el mundo público a partir de la conquista de derechos básicos ciudadanos. El ingreso de las mujeres al mundo del trabajo formal, la universidad y la conquista del sufragio son indicadores de esta idea de igualdad, y su propósito es alcanzar esferas de poder acaparadas por los hombres. Esta vía de emancipación de las mujeres es originaria y en ese orden se la considera en la contemporaneidad una vía tradicional, en tanto empieza a ser cuestionada por el pensamiento de la diferencia, como una postura que entiende "lo otro" en términos de lo mismo, es decir, en la homologación al modelo normativo del varón formal: algo materialmente imposible para el feminismo de la diferencia, pues implica omitir las más significativas diferencias, los sexos, a su vez principio de inteligibilidad de la cultura occidental (Femenías, 2012).

Según la periodización de Bellucci y Rapisardi (2001), en la década de 1930 se identifica un período de reflujo de las luchas feministas, dado que se reinstalan los modelos femeninos en el espacio privado y doméstico. Influyen en este momento, entre otras, el reconocimiento del derecho al sufragio de la mujer por parte de varios estados europeos, una de las grandes conquistas ciudadanas del momento. En la posguerra, a medida que se reconstruyen las economías de los países arrasados, el capitalismo difunde sus ideas consumistas y las mujeres rodeadas de comodidades se resguardan en los hogares. Se propaga la idea de mujer sustentada en una mística femenina vinculada al espacio doméstico y a la reproducción biológica.

En la década de los sesenta, el feminismo de la segunda ola amplía el ingreso de las mujeres a las universidades y espacios laborales, planteando el surgimiento de un sujeto 
colectivo de crítica y de producción teórica. La afirmación del momento se sustenta en una realidad específica vivida por las mujeres e inspirada en el imaginario de la superioridad de lo femenino sobre lo masculino, no pretendiéndola en términos de dominación sino de coexistencia pacífica. Es notoria la insistencia en deconstruir la definición de mujer impuesta por los hombres a través de la afirmación de una "esencia" femenina auténtica, generadora de relaciones con el mundo. En concreto, se cuestiona que si los términos de la ciudadanía han sido definidos por los varones, acceder a la misma es solo un modo de mimetización: por ende es una pérdida de la especificidad, lo cual le viene muy bien al patriarcado en tanto es un igualitarismo que no quebranta sus bases.

Las protagonistas de la diferencia, de este feminismo de la segunda ola los indican Bellucci y Rapisardi "encuentran palabras para definir su malestar en producciones pioneras, tales como El Segundo Sexo (1949) de Simone de Beauvoir, La Mística de la Feminidad (1963) de Betty Friedan, y La Dialéctica del Sexo (1970) de Shulamith Firestone" (2001: 12). Reiteran que está en juego la propia identidad, el reconocimiento de sí mismas; y a diferencia de las feministas de la primera ola, son discursos desde las mujeres, sobre las mujeres y para las mujeres.

Otros desarrollos importantes no se dan solo por la reivindicación de valores diferenciales (sensibilidad, afectividad, maternidad), sino por la atención a los debates sobre la sexualidad femenina, la subjetividad y el sexismo en la producción de conocimiento. La propuesta de la segunda ola no es homogénea, de hecho, finalizando la década de los 6o, grupos autónomos de mujeres se separan de las políticas revolucionarias de izquierda dominadas por hombres y dan origen al feminismo radical. Es entonces que se subdivide ideológicamente el feminismo en radicales y liberales. Para el feminismo radical, la supremacía masculina es la forma de dominación antigua y básica, ubicando así a las demás formas de opresión y explotación como extensiones de tal supremacía. Esta llega a ser una de las ideas discutidas por el feminismo crítico, que no necesariamente ve al patriarcado como opresión primaria, en detrimento de otras opresiones como las raciales, de orientación sexual o clase social.

Retomando la intención de este escrito, en cuanto a encontrar elementos compartidos en medio de la pluralidad del feminismo, podemos plantear como primer punto común que poner fin al patriarcado considerado como sistema de dominación básico (Millet, 1969) o como estructura de poder intersecta a otras opresiones derivadas de categorías raciales, de género y clase social ha sido y sigue siendo un compromiso.

La división de radicales y liberales no se desarrolló de modo tajante, pues las feministas radicales participaron también de las campañas por la igualdad de derechos. En ese contexto empieza a crecer el movimiento del feminismo lésbico, convirtiéndose de a poco en una fuerza importante y un desafío para el movimiento de mujeres, que tuvo que hacer frente a su prejuicio y asumir una tensión que incluso hoy está vigente; nos referimos a malestares reiterativos en espacios de feministas heterosexuales con 
feministas lesbianas, en los cuales las primeras no consideran prioritaria la problemática lésbica y las segundas temen que sus compañeras reproduzcan discriminaciones propias de la heteronormatividad. Con esto se empiezan a vislumbrar diversos retos para el movimiento, asociados a la ampliación del espectro de asuntos de los que se ocupa. A medida que entran en la esfera de influencia del movimiento más mujeres y que los temas se diversifican étnica, social y culturalmente, se generan rupturas y discontinuidades en los estilos feministas. Dichas diferencias son importantes para la continuidad de los movimientos sociales, pues sobre ellas surgen las redefiniciones de nuevas/os participantes; ampliando así los discursos y los sujetos.

Nos referimos no sólo a los posicionamientos de mujeres lesbianas, mujeres negras, o mujeres latinoamericanas, sino a sujetos de sexualidades no normativas; es decir, identidades y expresiones bisexuales, travestis, transgénero, entre otras, que subvierten la norma heterosexual y, al igual que las feministas, niegan la ideología de género y sus variadas tecnologías, cuestionando las vinculaciones de la sexualidad a la biología y al ámbito de lo privado.

Con estas ideas se vislumbra un segundo punto común en medio del plural ambiente feminista: romper con la adscripción que se hace a nivel sociocultural del sexo, el género y las identidades a las esferas íntimas y naturales.

\section{Reconceptualizaciones}

Sobre la base de los antecedentes mencionados, en el contexto occidental, en las décadas del 70 y 80 del siglo pasado un halo crítico reexamina las afirmaciones del feminismo de la primera y segunda ola, y genera concepciones particulares: a veces novedosas.

Los debates cambian en la medida en que ingresan otras voces de mujeres posicionadas críticamente frente a la visión occidental, blanca y heterosexual que venía caracterizando el movimiento. Dichas mujeres, negras, lesbianas, latinoamericanas, inmigrantes, entre otras, configuran el punto de vista del "otro" y a su vez dan lugar al denominado feminismo de la multiplicidad de diferencias (Bellucci y Rapisardi, 2001). Este se ocupa tanto de las diferencias de género como de las diferencias entre las mujeres, lo que implica una variedad de luchas y concepciones diversas acerca de los sistemas de dominación y opresión. Podemos pensar también esta corriente como parte de un feminismo crítico ante sí mismo y frente a momentos históricos y trayectorias. Muchas experiencias de opresión están no sólo vinculadas a la dominación masculina dentro de la propia cultura, sino a la hegemonía del mundo blanco occidental; por ello es necesario romper las categorías dicotómicas/rígidas que ocultan la pluralidad y conforman discursos totales y unitarios. El sexismo ya no se presenta como opresión aislada sino interconectada a racismo, antisemitismo, etnocentrismo, capitalismo, heterosexismo, entre otros. Ante 
la inexistencia de caminos puros o certeros para afrontar y transformar las desigualdades, brotan múltiples luchas que pueden ser diferentes entre sí, como diferentes son las mujeres de acuerdo a su condición de clase, etaria, cultural, étnica, y su opción sexual.

Parte de las características de este feminismo repensado o reconceptualizado se concentra en la construcción de posicionamientos críticos frente a cualquier tipo de dinámica homogeneizadora, heteropatriarcal, racista y colonizadora. Procura ser un feminismo consciente de sus propios prejuicios y de los diferentes modos en que las mujeres vivencian la dominación en razón de la dimensión étnico-racializada y de clase social. Así acordamos con Bell Hooks (1984) en concebir este conjunto de reconceptualizaciones como una teoría en proceso de elaboración a la que se debe también continuar analizando y explorando nuevas posibilidades.

Surge la inquietud sobre las traducciones de estas reconceptualizaciones en la región. A propósito, Francesca Gargallo concibe las particularidades de un feminismo nuestroamericano, considerando importante reconocer que la emancipación de las mujeres y las luchas sociosexuales en la región están demarcadas por determinaciones históricas y geopolíticas cuyas especificidades nos pueden distanciar incluso de los parámetros de libertad concebidos en Europa o Estados Unidos. Ejemplo de dichas determinaciones son resistencias colectivas, que si bien circulan en torno a la defensa de las mujeres y de quienes rompen la norma heterosexual van a ser luchas atravesadas por lógicas militaristas, racismo, pobreza y diferentes variables, leídas por ella como "expresiones materiales de la construcción de la colonialidad de América" (Gargallo, 2009: 16). Por eso, el debate alrededor de discursos y prácticas políticas feministas contemporáneas en Latinoamérica exige análisis y preocupaciones contextuales, que van más allá de un mero traslado discursivo europeo y estadounidense a las realidades cercanas.

Las condiciones simbólicas y materiales de las personas oprimidas en razón de la clase social, el género y la etnia en la región son tan propias que en ocasiones pueden requerir de posturas igualitaristas, o en otras de posturas que reivindiquen la diferencia. De esta manera, no se puede inferir unidad en las apuestas llevadas a cabo en el continente: así como habrá escenarios para actuar frente a la concepción de las mujeres y niñas como propiedad privada de los varones, habrá escenarios para actuar frente al desplazamiento forzado, frente a la legalización de la identidad de género, entre muchos.

A propósito de estas múltiples particularidades contextuales, Colombia es un territorio de disputa entre actores armados; escenarios coincidentes a situaciones de conquista y dominación que habilitan condiciones para la apropiación sexual de las mujeres de los grupos derrotados; cruenta estrategia usada para afirmar la superioridad del vencedor. Esto implicaría la reacción de un feminismo consciente de las determinaciones geopolíticas de los entornos.

Otros feminismos latinoamericanos confrontan el éxito del capitalismo en la destrucción de las culturas locales y se conectan "al clima continental reactivo de 
profunda crítica a la occidentalización de América y a sus secuelas de racismo y colonialismo que intentan reorganizarse en las ideas y las prácticas políticas del neoliberalismo" (Gargallo, 2007: 2).

Si bien, no es central a este artículo discutir los panoramas complejos en los cuales incide el feminismo actual, sí podemos prever innumerables cruces de opresiones que enfrentan los sujetos sexuados en Latinoamérica. Estos pueden ser analizados a partir del marco de ideas del feminismo de la otredad, que invita a posicionarse críticamente frente a "toda identidad que se diga hegemónica y monolítica, esencializante y naturalizante" (Flores, 2008).

\section{Sobre el género}

En este sentido, el género deja de ser la simple imposición de roles, normas y comportamientos sociales y culturales; cualquier interpretación de la categoría "mujer" como categoría unitaria es derrocada y la diferencia se convierte en un concepto clave que requiere claridad y de análisis. Un propósito de estas reconceptualizaciones del feminismo contemporáneo es ofrecer a su vez líneas de intervención para estrategias y acciones concretas, al igual que apostarle a un feminismo situado en escenarios determinados étnica, racial y culturalmente. Así, el concepto de patriarcado no puede concebirse indiferenciado de las desigualdades de raza y clase, conduciendo así a interconectar otras variables. Una de aquellas discusiones surgió en 1977, cuando La Colectiva del río Combahee ${ }^{1}$ publica en un manifiesto, que considera que la política de la sexualidad desplegada por el sistema patriarcal se adueña de las vidas de las mujeres negras, al igual que la política de clase y raza; en ese sentido, resulta difícil separar la opresión racial de la clasista y de la sexual, pues dichas opresiones son una experiencia simultánea en sus vidas (Combahee River Collective, 1977). Al respecto, Avtar Brah menciona que "las estructuras de clase, racismo, género y sexualidad no pueden tratarse como variables independientes porque la opresión de cada una está inscrita en las otras es constituida por y es constitutiva de las otras" (2004: 112).

La división sexo/género también es puesta en duda al considerar argumentos que indican que la diferencia sexual no está alejada ni desligada de las atribuciones, las ideas, las representaciones y las prescripciones sociales propias de la ideología de género. En este sentido, Gayle Rubin define el sistema sexo-género como el "conjunto de disposiciones por el que una sociedad transforma la sexualidad biológica en productos de la

1. Combahee River Collective se conformó en 1974 por varias mujeres negras lesbofeministas. Su nombre provino de la acción guerrillera dirigida por Harriet Tubman en 1863 en el estado de Carolina del Sur, en que liberó más de 750 esclavos y esclavas. Es laúnica campaña militar, en la historia norteamericana, planeada yllevada a cabo por una mujer. 
actividad humana y en el cual se satisfacen esas necesidades humanas transformadas" (1975: 97); diez años más tarde esta misma antropóloga critica su denominación de sexo-género, por considerar que de allí se podría desprender la idea de que el sexo es una realidad siempre constante y universal, y por esto "natural" o ajena a la historia.

La categoría género se consolida como herramienta analítica y conceptual en los años 70 y dentro del feminismo, para expresar la construcción cultural de la diferencia sexual, con ella se esclarece no solo la no-naturalidad en la constitución de hombres y mujeres, sino la relación de poder existente entre los dos sexos en lo social, material y simbólico (Curiel, 2010). Justamente el énfasis en el género como uno de los tantos modos a través del cual opera el poder es un tercer punto en común y a destacar en medio de la diversidad de apuestas feministas.

La idea del género como contenedora de toda una fuerza cultural a descargar sobre una superficie corporal pasiva, sigue siendo difundida por varias disciplinas, y ámbitos sociales y estatales. Al respecto, Judith Butler desarrolla diversas críticas: hacia 1989 confronta los planteamientos que defienden un significado del género limitado a las concepciones aceptadas y difundidas de masculinidad y feminidad: considera que el feminismo tradicional idealiza ciertas expresiones de género que no hacen más que producir nuevas formas de jerarquía y exclusión. El género emerge como la forma rígida de la sexualización de la desigualdad entre el hombre y la mujer (Butler, 2007). En palabras de Teresa De Lauretis (2000), es un aparato ideológico al que el cuerpo sexuado sirve de sustento material.

Judith Butler concibe al género a la luz de su teoría de la performatividad; el género como expectativa acaba produciendo el fenómeno mismo que anticipa; es decir, las personas actúan promoviendo una construcción cultural que se predice antes del nacimiento. La performatividad no es entonces un acto único, sino una repetición, un ritual que consigue su efecto a través de su naturalización en un cuerpo como territorio. Lo que consideramos una esencia interna del género se construye a través de un conjunto de actos pautados por la adaptación del cuerpo a las características genéricas. Esto demuestra que lo que concebimos como un rasgo interno de nosotros/as mismos/as es algo que producimos a través de ciertos actos corporales y gestos naturalizados. Butler enfatiza en que dar por hecho esas verdades es opresivo. La misma autora refiere que el género como categoría analítica ha sido controlado y vigilado por medio de la afirmación de la norma heterosexual. Dicho control implica una operación de poder destacadamente normativa y violenta en el sentido en que impone tipos ideales de género. Así es posible encontrar explicaciones que remiten a las condiciones de inteligibilidad del género, también lo es encontrar explicaciones normativas que intentan responder cuáles expresiones de género son aceptables y cuáles no.

Lo anterior es un llamado a poner en duda la realidad del género; aunque esta tensión genere la sensación de un problema o disputa vigente y relevante, es necesario ahondar 
en los debates feministas actuales sobre la indeterminación del género. La autora invita a no tomarse en serio el género, a no concebirlo de manera rígida y estricta, considerando que "es indispensable para el feminismo la risa frente a las categorías serias" (Butler, 2007). Descentralizar entonces el argumento de la construcción social y cultural prometida para la categoría género es un ejercicio que pone sobre la mesa una concepción del cuerpo y del sexo que trasciende la pasividad que le era asignada. El límite y la superficie de los cuerpos están construidos políticamente, es preciso desnaturalizarlos y otorgarles un nuevo significado como categoría corporal más allá del marco binario de los sexos. Así aclara Butler que el sexo no crea al género y no se puede afirmar que el género refleje o exprese el sexo.

Teniendo en cuenta la variabilidad de la cuestión en este planteamiento, vale la pena distinguir algunas nociones que rompen con la idea de que el mundo está conformado solo por dos sexos complementarios: nos referimos a la necesidad de contar con elementos que permitan verbalizar las excepciones al "binarismo" sexual. Para ello retomaremos los planteamientos de Gabriela Castellanos (2006). Las identidades sexuales remiten claramente a realidades psíquicas de cada individuo (subjetivas). En la visión de Butler, la identidad es una "construcción discursivamente variable" del yo y de sus actos. "Sentirse" hombre o mujer, femenina o masculina es por lo tanto el resultado de un proceso performativo que se realiza en un contexto cultural determinado. De modo distinto, las orientaciones sexuales remiten a la atracción sexual y afectiva hacia personas del mismo sexo, del sexo opuesto o de ambos sexos, en este marco se habla de personas heterosexuales, homosexuales y bisexuales. Los estilos de género son modos culturales de expresión (actuar y hablar) que reconocemos como típicos de uno u otro sexo, son modos de comunicación con el mundo. En relación a estos, es necesario tener en cuenta que se ubican en realidades culturales, y en esa medida son históricos pues evolucionan/ cambian en el tiempo; también son étnicos, pues difieren de un grupo social a otro, se adquieren, no son innatos. Nuestras sociedades están atravesadas en todas sus esferas políticas, legales, religiosas o económicas por dos estilos discursivos relacionados culturalmente con el género femenino o masculino. La expectativa es que el sexo biológico coincida con uno de aquellos estilos, cuando esto no sucede así hay castigo y exclusión. No obstante, todos los sujetos son susceptibles a emplear el estilo del sexo opuesto. Con ello nos reafirmamos en las proposiciones de un feminismo crítico, expresado en ideas como las de Butler, que dice que si el género y el sexo son radicalmente diferentes, no se puede defender que ser de un sexo determinado conduzca a ser de un género determinado; "mujer no es necesariamente la construcción cultural del cuerpo femenino y hombre tampoco representa obligatoriamente a un cuerpo masculino" (Butler, 2007).

Aunque los estilos femeninos y masculinos no necesariamente corresponden al sexo biológico, es problemático desigual e injusto cuando se prefieren los estilos masculinos en detrimento de los femeninos, las actitudes verbales y/o gestuales 
responden a ideologías. Por ejemplo, las tensiones en los movimientos socio sexuales o aquellos que reivindican las sexualidades no normativas crecen al interior de los mismos por reproducir supremacías gays masculinas que se traducen en el rechazo o la exclusión de apuestas lésbicas o trans. Es necesario traer al caso los aportes de la epistemología feminista, la cual se encarga de desmantelar las estructuras de pensamiento dicotómicas y jerarquizadas que traspasan todos los ámbitos de la vida social; estas dicotomías reflejan que la cultura enseña a valorar el estilo masculino por encima (y como opuesto) del femenino.

Volviendo a la preocupación por las pertinencias que tienen estas reconceptualizaciones del feminismo en la región, es importante mencionar la asignación de sentidos

y críticas que también se han dado a la categoría género por parte del movimiento feminista autónomo latinoamericano. Este movimiento teórico y político, posicionado en claro antagonismo a todo tipo de dogmas, mandatos y regulaciones, se siente heredero de los legados del feminismo radical de los años 70 y de las feministas que a finales de los 80 anunciaron el riesgo político que se corría cuando importantes sectores del feminismo se aliaban con la cooperación internacional, el sistema de Naciones Unidas, el Estado y sus instituciones. Este feminismo situado y antirracista recoge el movimiento de mujeres latinas, chicanas y negras en los EE.UU. y sus continuidades en Latinoamérica y el Caribe; se nutre además de los aportes de las lesbianas feministas en lucha contra el régimen de la heterosexualidad obligatoria y reconoce a las mujeres como categoría política y no natural. La autonomía es concebida como un acto de profunda disidencia contra toda lógica de dominio patriarcal, occidental y capitalista, que se expresa en prácticas políticas de los gobiernos, la cooperación internacional y los espacios transnacionales donde una elite experta separada de los movimientos produce las agendas de las políticas locales. A esto justamente llaman tecnocracia del género y la consideran un invento de estados e instancias supraestatales. Consideran que hay que instalarse críticamente frente al uso que la institucionalidad hace de la categoría género, pues la apropiación del término no es suficiente para fortalecer comunidades y movimientos sociales; su intención no se dirige entonces al buen funcionar del Estado sino a la consolidación política de las bases sociales.

\section{Sobre el sexo}

Las reconceptualizaciones originadas con el surgimiento del feminismo de la multiplicidad de diferencias han concebido la categoría sexo más allá de lo físico y lo corporal; es decir, otorgándosele sentidos ideológicos y culturales. Judith Butler aborda la categoría sexo como normativa y parte de una práctica reguladora que produce los cuerpos que gobierna. El sexo tiene entonces el poder de producir, demarcar, circunscribir y diferen- 
ciar los cuerpos que controla (Butler, 2007). Lo anterior es complementado por Maffia y Cabral (2003) al sostener que el sexo anatómico y su presunta dicotomía es producto de una lectura ideológica. Una ideología de género que antecede la lectura misma de los genitales, que no permite hablar de un sexo natural, y que es lo suficientemente fuerte como para disciplinar los cuerpos cuando no se adaptan cómodamente a lo que se espera de ellos. El sexo no es estático y sí es una de las normas mediante las cuales puede llegar a ser viable; es una norma que califica un cuerpo para toda la vida dentro de la esfera de la inteligibilidad cultural.

El proceso de repensar y rever conceptos y prácticas identificadas en las anteriores corrientes del feminismo propone un nuevo sujeto de la conciencia feminista contemporánea. Teresa De Lauretis considera que ya no es sujeto definido, teniendo en cuenta el único eje del género: la oposición hombre-mujer.

(...) este sujeto es mucho menos puro. Así, es con más probabilidad ideológicamente cómplice del "opresor", pudiendo ocupar su lugar en determinadas relaciones socio-sexuales, aunque no en otras (...) no es un sujeto unitario, siempre igual a sí mismo, dotado de una identidad estable; ni un sujeto únicamente dividido entre masculinidad y feminidad. Es, al contrario, un sujeto que ocupa posiciones múltiples, distribuidas a lo largo de varios ejes de diferencia, y atravesado por discursos y prácticas que pueden ser y a menudo lo son recíprocamente contradictorios. (De Lauretis, 200o).

Esto nos permitiría (si fuera el caso) hablar en concreto de las contradicciones de estos sujetos y los debates que actualmente suscitan. Por lo pronto conviene antes de acusar de modo generalizado cuando son más o menos políticos, más o menos transformadores, más o menos agentes de cambio, más o menos institucionalizados, más o menos autónomos admitir que son sujetos que exceden de múltiples formas las categorías fijas impuestas por las instituciones.

$\mathrm{Si}$ consideramos las características socio-culturales vigentes en los contextos latinoamericanos, este sujeto tendrá diversos condicionantes apuntados por los términos de reconocimiento desarrollados por Judith Butler; quien invita a tener en cuenta la localización de la "reconocibilidad"; es decir, la cantidad de normas sexuales y de género que determinan quién es considerado como sujeto y quién no. (Butler, 2009).

Todas las contribuciones señaladas nos hablan de una teoría feminista que le apuesta no sólo a la inclusión de nuevas categorías, sino que a la vez representa y pone en marcha una transformación de la conciencia histórica. Según De Lauretis la transformación comporta un deslizamiento: "dejar o renunciar a un lugar que es seguro, que es 'casa' en todos los sentidos socio geográfico, afectivo, lingüístico, epistemológico por otro lugar, desconocido, en el que se corre un riesgo no solo afectivo sino también conceptual" (De Lauretis, 2000).

Tras aproximarnos a algunos de los puntos que problematizan las categorías de géneroy sexo, en un marco que registra una concepción del feminismo más comparativa, rela- 
cional y asentada históricamente, suscribimos una perspectiva que en palabras de Avtar Brah "clama por un cuestionamiento continuo del esencialismo en todas sus variantes" (Brah, 2004). De la misma manera, considera Butler que "los cuerpos sexuados pueden ser de muchos géneros diferentes, y además el género en sí no se limita solamente a los dos géneros habituales" (Butler, 2007). Las autoras mencionadas desafían en distintos textos críticos feministas el modo en que la racialización, la heterosexualización, la polarización de clase y la creación de pobreza operan dentro del feminismo occidental. Por otra parte, conciben el género ambiguo e impreciso, en transformación, actividad constante y repetida; coinciden además en abordar un punto de vista excéntrico ${ }^{2}$, que aportaría positivamente al contexto de repensar el movimiento. Butler invita a abrir las posibilidades del género a través del debate conceptual enmarcado en una flexibilidad teórica; su pretensión en desnaturalizar el género tiene origen en el deseo de contrarrestar la violencia normativa que conlleva. Aclara además que todas las formaciones discursivas son un lugar de poder, el poder se constituye de forma performativa en y a través de prácticas económicas, políticas y culturales.

\section{Sobre la heterosexualidad}

Otro aspecto propio de este marco de reconceptualizaciones es el análisis crítico de los discursos que han legitimado la institución heterosexual, conduciendo así a concebirla no como mera orientación sexual sino como un régimen con un decidido carácter institucional y obligatorio. Cabe anotar que pese a las ideas de diversas autoras desde la década de los 70 y 80, la heterosexualidad como institución sigue inserta y es poco cuestionada en las luchas de los movimientos de mujeres, de los movimientos feministas y de los movimientos sociosexuales. Al respecto, De Lauretis, menciona que a través de los siglos el discurso filosófico ha excluido otras sexualidades, asegurando así el contrato heterosexual: "La construcción y la apropiación de lo femenino para uso del erotismo masculino asegura la heterosexualidad o la homosexualidad del pacto social, en virtud del cual todas las sexualidades, todos los cuerpos y todos los 'otros' permanecen vinculados a una ideal e ideológica jerarquía masculina que los define y determina su significado y valor 'social'" (De Lauretis, 200o).

Siguiendo estos planteamientos en torno al lugar que la heterosexualidad ocupa en nuestras sociedades, es importante mencionar la herencia directa del discurso propio de un pensamiento filosófico, tradicionalmente falocéntrico y patriarcal. Al respecto,

2. El punto de vista excéntrico es una posición desarrollada por Teresa De Lauretis para valorar las posibilidades de resistencia y la capacidad de obrar a través de formas de sexualidad no normativas; las denomina también prácticas sexuales excesivas, subversivas, perversas que configuran una posición discursiva en exceso; es decir, no reasimilable por la institución socio-cultural de la heterosexualidad. (De Lauretis, 2000). 
Paco Vidarte dice que el mismo crea estructuras de pensamiento que se reproducen en occidente y "convierte a los sujetos en entidades invariables" (2007: 12); por lo tanto, la heteronormatividad dentro de este discurso juega un papel clave, convertida en algo universal, intemporal e invencible. Por su parte, Monique Wittig se pone del lado de quienes han sido oprimidos/as por el contrato heterosexual y sus discursos, comprendiendo la dificultad para cuestionarlos en tanto institución o régimen político. "El conjunto de estos discursos levanta una cortina de humo de ruido y confusión para los oprimidos, que les hace perder de vista la causa de su opresión y los sume en una suerte de vacío ahistórico" (Wittig, 2007: 1).

En el intento de entender la heterosexualidad en su sentido abstracto o como institución civil, Judith Butler (2007) rescata en El género en disputa la genealogía propuesta por Michel Foucault como método de cuestionamiento crítico que busca los orígenes no del género, ni del deseo femenino, ni de una identidad sexual verdadera, sino de los intereses políticos que hay en el fondo de su existencia; refiriéndose también así a la necesaria búsqueda de los orígenes de los intereses políticos y los intereses económicos que enmarcan a la heterosexualidad obligatoria y que hacen que clasifique los cuerpos sexuados en masculino y femenino.

Frente a las maneras de asumir la heterosexualidad podemos encontrar quienes la asumen como una orientación sexual más dentro del abanico de posibilidades o preferencias erótico-afectivas; o quienes desde posturas más críticas la entienden como norma, régimen político, institución, y especialmente una ideología asentada sobre la diferencia sexual, la cual despliega efectos materiales y simbólicos a la hora de encontrarse con elementos conservados aún como la familia, el matrimonio, la pareja u otras definiciones existentes sobre la reproducción y la propiedad. En este sentido, fue la italiana Carla Lonzi en 1971, quien por vez primera planteó el carácter político de la heterosexualidad en el feminismo, en su texto Escupamos sobre Hegely otros escritos sobre Liberación Femenina (1978), define la heterosexualidad como un dogma que considera a las mujeres como complementos "naturales" de los hombres, relación que se sostiene a través de la reproducción. En 1975, aparece The Normative Status of Heterosexuality escrito por el Colectivo de lesbianas feministas Purple September de Amsterdam, en donde se afirma que una de las definiciones implícitas de la feminidad es la heterosexualidad y que el objetivo general del condicionamiento femenino es hacer que las mujeres se perciban a sí mismas y a sus vidas a través de ojos masculinos, lo que da a la heterosexualidad un estatuto normativo (Espinosa, 2007).

De Lauretis dice que dentro del movimiento social y teórico feminista la heterosexualidad es vista en un principio como práctica sexual privada y más tarde como institución civil, connotación usada desde el siglo XX para designar cualquier elemento organizado de una sociedad o cualquier proceso, abstracto, objetivo y sistemático. Quien ampliamente abordó el carácter institucional y obligatorio de la heterosexualidad 
fue Adrienne Rich en su texto de 1980 La heterosexualidad obligatoria y la existencia lesbiana. Rich entiende la heterosexualidad como parte de la variedad y cantidad de medidas diseñadas para mantener a las mujeres dentro de los linderos sexuales masculinos; en este orden, opta por comprender este tema desde una perspectiva distinta a la usual explicación de práctica sexual, preferencia, orientación o elección para las mujeres. Para ella la heterosexualidad constituye una imposición institucionalizada y naturalizada para asegurar el derecho masculino al acceso físico, económico y emocional de las mujeres (Rich, 1985).

Es usual que, dado el uso común que tiene el término, a la hora de pensar la heterosexualidad nos dirijamos principalmente a su definición de acto o relación personal entre dos individuos antes que seguir su sentido abstracto o como institución civil; tal como lo empezaron a plantear colectivos de feministas lesbianas afroamericanas en la década de los 80. Señala De Lauretis que no se trata de privilegiar el heterosexismo sobre otros sistemas de opresión (capitalismo, racismo, colonialismo) sino de entender su carácter institucional y los aparatos socioculturales que se derivan del mismo (De Lauretis, 200o).

El concepto de institución de la heterosexualidad obligatoria, permitirá arribar a un análisis más adecuado respecto al lugar que la heterosexualidad ocupa en nuestras sociedades, de la manera en que funda tanto el género, la sexualidad, los modos de relación entre los sujetos y de pensamiento sobre los sujetos. Como veremos, pensar la heterosexualidad como institución social sería una noción clave para la teoría feminista en su análisis sobre la construcción del patriarcado. (Espinosa, 2007).

Si bien han transcurrido casi tres décadas de planteado el problema, el análisis de la heterosexualidad como institución sigue siendo reciente dentro de la teoría feminista, ni si quiera es aceptado o visto de la misma forma entre las feministas. No podemos afirmar que en la actualidad la comprensión del carácter normativo o institucional de la heterosexualidad se haya difundido plenamente en los contextos latinoamericanos. Sin duda, sigue siendo un tema a debatir dentro de los movimientos feministas y sociosexuales, y a militar en los espacios públicos compartidos entre la sociedad y el Estado. A pesar de que sus planteamientos vienen desde los 8o, en muchos escenarios del presente la heterosexualidad obligatoria no se asume como tal, ni se relaciona como fundante del género, la sexualidad y las relaciones interpersonales; tampoco es vista como herramienta clave de un patriarcado que reacciona cada vez más fuerte ante el avance del feminismo. Al respecto, Teresa de Lauretis plantea la costumbre mental de asociar el término para nombrar prácticas sexuales entre una mujer y un hombre en una dimensión privada. Esto indudablemente genera el efecto de naturalizar la heterosexualidad y ver las sexualidades alternativas como no-naturales y por lo tanto desviadas o equivocadas. Estas asociaciones tienden además a "oscurecer la no-naturalidad de la misma heterosexualidad, o sea, el hecho de ser una construcción social, su dependen- 
cia de la construcción semiótica-ideológica del género más que de la existencia física (natural) de dos sexos" (De Lauretis, 2000: 125).

Otro planteamiento que alude a la fuerza y la vigencia de la hegemonía heterosexual lo hace Butler al mencionar que "una es mujer en la medida en que funciona como mujer en la estructura heterosexual dominante, y poner en tela de juicio la estructura posiblemente implique perder algo de nuestro sentido del lugar que ocupamos en el género" (Butler 2007: 12). Retoma en su obra a Monique Wittig cuando plantea que la heterosexualidad tiene lugar dentro del discurso para comunicar una amenaza "serás heterosexual o no serás", situaciones que pueden dar lugar también a la homofobia o a diversos prejuicios sociales frente a las sexualidades no normativas (Butler, 2007: 232). De esta forma, es la institución social de la heterosexualidad y no un dato biológico la que reproduce y regula mediante el género una específica diferencia de poder entre hombres y mujeres. Reconocemos bajo esta mirada que el privilegio masculino no constituye algo a lo que fácilmente se pueda renunciar en un acto de voluntad, permea diversas dimensiones socioculturales, políticas y subjetivas al haber constituido sujetos acordes a contrato social heterosexual; es decir, sujetos clasificados en dos géneros que a la vez se excluyen y se implican.

La idea de "contrato heterosexual" ha sido propuesta por Monique Wittig (2006) para precisar el pacto por medio del cual las distintas disciplinas epistemológicas de la modernidad se asientan en una naturalización de los géneros masculinos y femeninos, dando por hecho que la oposición y la complementariedad entre ellos es el fundamento de la sociedad. Dicho acuerdo vigente aún entre sistemas teóricos o epistemológicos sencillamente no cuestiona la oposición sociosexual entre hombres y mujeres, que hasta el día de hoy pareciera en todos los contextos la base necesaria y fundante de la cultura. Estas ideas nos llevan a destacar un cuarto punto en el siguiente apartado, en tanto consideramos está cargado de potencialidad y utilidad política en distintos escenarios (incluso feministas) en los que no se ha discutido a profundidad: el carácter institucional y obligatorio de la heterosexualidad.

\section{Feminismos plurales, continuidades y compromisos}

Hemos abordado hasta aquí elementos claves para la comprensión de un feminismo que ha transitado diversos contextos sociohistóricos, desplegando en cada uno de ellos varias ramificaciones que plantean múltiples modos de asumirlo y de nombrarlo. Con lo complejo y contradictorio que resulta examinar parte de las propuestas y agencias sostenidas a lo largo del tiempo, nos interesa afrontar la sensación de dispersión y en ocasiones de condescendencia de un movimiento social cada vez menos puro, menos identificable, pero no por ello menos político. En ese orden, consideramos que coexisten 
en la actualidad puntos comunes y transversales a décadas cargadas de movilizaciones ilustradas anteriormente con el feminismo de la igualdad, el feminismo de la segunda ola y el feminismo de la multiplicidad de diferencias. Mencionar dichos puntos no resuelve del todo la angustia activista, intelectual y personal que podamos sentir hoy en contextos donde el patriarcado parece recrudecerse y la lucha feminista aplacarse, pero sí trae de vuelta y a modo de reconocimiento elementos con relevancia política que no hay que perder de vista en los escenarios cotidianos.

Un primer elemento a destacar es el compromiso básico del movimiento teórico y político feminista en dar fin al patriarcado, de tal forma que se subvierta una supremacía masculina considerada referente para el desarrollo de todos los ámbitos de la vida social y por lo tanto subordinadora de valores femeninos expresados en el mundo material y simbólico. Pese a la diversidad de posturas generadas en distintos momentos históricos y culturales del movimiento, la identificación de este sistema de opresión es clave y parte del trabajo académico y militante pone de relieve la necesidad de ubicarlo y contextualizarlo permanentemente para avanzar en el reto cultural de entenderlo tanto como las exclusiones, discriminaciones y violencias que genera.

En los primeros apartados de este escrito se planteó cómo este concepto fue considerado en el marco del feminismo de la segunda ola especialmente por las feministas radicales como un sistema de dominación originario o primario desde el cual se desprendían otro tipo de exclusiones racistas y capitalistas. Posteriormente, un panorama feminista crítico y autocrítico, con el sello blanco y occidentalizado de las líneas tradicionales del movimiento, replantea el concepto enlazándolo a otras dominaciones; así pasó del carácter fundante de las desigualdades a un carácter mucho más complejo en donde su existencia está en relación a otras categorías sociales. Pese a estas divergencias, el poder patriarcal solo o acompañado de otros poderes es un sistema frente al cual los feminismos en todos sus estilos y estrategias siguen generando antagonismos e incluso militancias; estas implican usarle como concepto para nombrar rasgos y características de las culturas o para poder posicionar la idea de que el feminismo lucha en contra de este sistema particular y no en contra de todos los hombres.

Otro aspecto compartido o común a los variados modos de construir y actuar en nombre del feminismo es la necesidad de romper con la adscripción sociocultural del sexo, el género y las identidades a las esferas íntimas y naturales. En este orden, es preciso reconocer que la naturaleza sigue situada en las estructuras de pensamiento como fuerza explicativa: en ámbitos públicos y privados, distintas realidades sociales son comprendidas desde la dicotomía natural/no natural; y aquí son también protagonistas las tecnologías empleadas por la ideología de género y heterosexista. Aunque desde la década del 80 fuertes confrontaciones derivadas de la autocrítica develan un feminismo cercado por contradicciones y paradojas, es posible pensar que el intento de romper imágenes y representaciones sociales ligadas a una incues- 
tionable naturaleza sigue siendo relevante en las apuestas y prácticas políticas de dichos movimientos sociales. Esto es políticamente pertinente en contextos locales y regionales en donde las instancias de poder están fuertemente influenciadas por las religiones, y donde parece que tienen como prioridades en sus agendas de trabajo el desmonte de las conquistas legales, educativas y culturales logradas por los movimientos de mujeres y sociosexuales.

La comprensión del género no solo como construcción sociocultural de la diferencia sexual sino como uno de los tantos modos a través del cual opera el poder, constituye un tercer punto a tener en cuenta en este intento de destacar en qué nos mantenemos de acuerdo. Dicha asignación de sentidos se fortalece a mediados de los setenta cuando los feminismos participan de muchos de los aspectos de las corrientes marxistas, psicoanalíticas, críticas de la metafísica, estructuralismo, posmodernismo, etc. En este sentido, se extiende en los feminismos que la estructura de relaciones entre hombres y mujeres es una estructura de poder que asegura la dominación de los primeros sobre las segundas.

Es entonces una continuidad, entre muchas rupturas, el entendimiento del género como una relación de poder. Su validez política la sustenta Teresa De Lauretis al plantear que el análisis feminista de las relaciones se fundó inicialmente sobre la noción de la diferencia sexual u oposición entre mujeres y hombres; de esta manera remarca que el análisis sigue siendo en varios contextos, incluso feministas, aplicado solamente sobre este eje del género. Aunque se asuma que ser hombre y ser mujer son categorías socialmente construidas, continúa también la idea de que existen dos sexos que se complementan y que además son datos preexistentes (De Lauretis, 2000). Con lo anterior se omite la jerarquía y la relación vertical entre dichos opuestos femeninos y masculinos, a pesar de que en 1986 Joan Scott hubiese definido de manera contundente al género no solo como "un elemento constitutivo de las relaciones sociales que se basa en las diferencias entre los sexos" sino como "una forma primaria de las relaciones de poder" (Scott, 1990:44). A su vez en sociedades donde el termino género ha sido cooptado por las lógicas gubernamentales y de la cooperación internacional asumido como sinónimo de "mujeres", es prioritaria su distinción como forma de ejercer el poder.

Un último elemento clave, compartido principalmente entre las apuestas de un feminismo crítico y contemporáneo y con relevancia política actual, es la consideración del carácter institucional y obligatorio de la heterosexualidad. Hoy se encuentran distintos escenarios sociales cercanos donde converge y se sostiene con ímpetu la idea de la heterosexualidad como orientación sexual o como relación en el ámbito privado entre hombre y mujer; su dimensión normativa e ideológica no es reconocida y son poco visualizadas las opresiones derivadas de esta norma. Dada la fuerza de los discursos de poder que movilizados y encarnados por las elites dominantes, afianzan y sostienen a partir de una serie de dispositivos (medios de comunicación, iglesia, entre otros) la dominación y el control de todos los territorios de la subjetividad humana, es 
fundamental continuar y fortalecer la discusión y el debate frente a los modos en que esta lógica heterosexista disciplina y domestica decididamente los cuerpos.

Judith Butler (2007) menciona que nada hay más fuertemente imbricado en la identidad que el cuerpo mismo. Ante este efecto duradero de la heterosexualidad naturalizada, el pensamiento crítico, la reflexión teórica sobre la cultura y el mismo pensamiento feminista siguen llamados a su revisión.

Hemos planteado cuatro aspectos que desde nuestra perspectiva coinciden en el marco de la diversidad de discursos y prácticas feministas contemporáneas; dichos elementos son a su vez vigentes y pertinentes en contextos latinoamericanos donde confluyen tanto apuestas autónomas (en antagonismo con la institucionalidad) como apuestas integracionistas (en afinidad con la institucionalidad). Justamente, se resaltan aquellos elementos especialmente valiosos o acertados porque tenemos el convencimiento de que los feminismos en constante flujo no tienen motivos para avergonzarse. Lo cierto es que las transformaciones y los cambios que propone no son solo los que se dan en las macro estructuras sino que también son y con sentidos igualmente políticos los que ocurren en lo cotidiano, en los espacios micro y simbólicos, en donde a nivel personal y colectivo se puede empezar a ver lo que antes no se veía y emprender así múltiples ideas y acciones de cambio.

\section{Referencias}

BUTLER, J. (2009). “Performatividad, precariedad y políticas sexuales”, AIBR Revista de Antropología Iberoamericana, 4(3).

BUTLER, J. (2007). El género en disputa: el feminismo y la subversión de la identidad, Barcelona: Paidós.

BELLUCCI, M. y Rapisardi, F. (2001). "Alrededor de la Identidad. Las luchas del presente”, Nueva Sociedad (162).

BRAH, A. (2004). “Diferencia, diversidad y diferenciación”, en AA.VV. Otras inapropiables. Feminismo desde las fronteras, Madrid: Traficantes de sueños.

CASTELLANOS, G. (2006). Sexo, género y feminismo. Tres categorías en pugna, Cali: Centro de Estudios de Género, Mujer y Sociedad/ La Manzana de la Discordia, Universidad del Valle.

COMBAHEE RIVER COLLECTIVE (1977). Manifiesto Colectivo del Río Combahee, una declaración negra feminista, Disponible en https://we.riseup.net/radfembr+spanish/manifiesto-colectiva-del-rio-combahee-unadeclarac

CURIEL, O. (2010). El régimen heterosexual de la nación. Un análisis antropológico lésbico-feminista de la Constitución Política de Colombia de 1991, Bogotá: Universidad Nacional de Colombia, Facultad de Ciencias Humanas, Departamento de Antropología. 
DE LAURETIS, T. (200o). Diferencias: etapas de un camino a través del feminismo, Madrid: Horas y horas.

DE SOUZA SANTOS, B. (2001). “Los nuevos movimientos sociales”, en: Observatorio Social de América Latina (OSAL), (5), Buenos Aires, CLACSO.

ESPINOSA, Y. (2007). Escritos de una lesbiana oscura: reflexiones críticas sobre feminismo y política de identidad en América Latina, Buenos Aires-Lima: En la Frontera.

FEMENÍAS, M. L. (2012). Sobre sujeto y género. (Re) lecturas feministas desde Beauvoir a Butler, Rosario: Prohistoria Ediciones.

FLORES, V. (2008). "Potencia tortillera: un palimpsesto de la perturbación”, disponible en http:// escritoshereticos.blogspot.com

GARGALLO, F. (2007). "Feminismo Latinoamericano", en: Revista venezolana de estudios de la mujer, (28), Caracas.

GARGALlO, F. (2009). "Pensando en los feminismos de Nuestra América. Percepciones de qué es hegemónico y colonial en los feminismos continentales", texto para la reflexión acerca de una investigación en acto. Socializado en el Seminario Permanente de Filosofía Nuestroamericana, de la UACM.

GARGALLO, F. (2012). "La urgencia de retomar nuestra radicalidad”, en: Pensando los feminismos en Bolivia, Serie Foros 2, Bolivia.

HOOKS, B. (1984). "Mujeres negras. Dar forma a la teoría feminista”, en AA.VV., Otras inapropiables. Feminismo desde las fronteras, Madrid, Traficantes de sueños.

MAFFIA, D. y Cabral, M. (2003). "Los sexos, son o se hacen", en Maffia, D. Sexualidades Migrantes, Género y Transgénero, Buenos Aires: Editorial Feminaria.

MILLET, K. (2010). Política sexual, Madrid, Cátedra.

RICH, A. (1985 [1980]). "La heterosexualidad obligatoria y la existencia lesbiana”, Revista Feminista Nosotras que nos queremos tanto, (3), Madrid.

RUBIN, G. (1975). “El tráfico de mujeres: notas sobre la economía política del sexo”, en: Navarro, M y Stimpson, C. (comps.), ¿Qué son los estudios de mujeres? Buenos Aires: Fondo de Cultura Económica.

SCOTT, J. (1990). “El género. Una categoría útil para el análisis histórico” En Nash y Amelang (eds.) Historia y género: las mujeres en la Europa moderna.

VIDARTE, P. (2007). Ética Marica. Proclamas libertarias para una militancia LGTBQ, Barcelona-Madrid: Egales.

WITTIG, M. (2007). El pensamiento heterocentrado y otros ensayos, Barcelona-Madrid: Egales. 